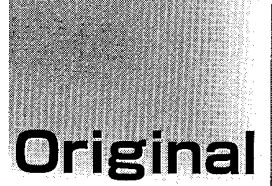

Received

July 11,2005

Revision accepted

Nov. 1, 2005

Code No. 522

\section{Measurement of Modulation Transfer Functions for Liquid Crystal Displays by Rectangular Waveform Analysis}

\author{
AKIKO HORII, AYA CHIHARA, ${ }^{1)}$ KATSUHIRO ICHIKAWA, ${ }^{2)}$ \\ YOSHIE KODERA, ${ }^{2)}$ MITSURU IKEDA, ${ }^{2)}$ \\ and TAKEO ISHIGAKI
}

\begin{abstract}
Graduate School of Medical Sciences, Nagoya University
1 ) Department of Radiology, Saishunso National Hospital

2) School of Health Sciences, Nagoya University
\end{abstract}

\section{Introduction}

In current medical imaging diagnosis, new diagnostic techniques using image viewers equipped with a cathode ray tube (CRT) display or liquid crystal display (LCD) have replaced the conventional film-based diagnostic techniques. It can be expected that this trend will continue to increase in the future. With this change, it is becoming important to evaluate the characteristics of displays and to carry out maintenance management in medical facilities that use CRT displays and LCDs. Therefore, as one form of determining the image quality of a display, modulation transfer function (MTF) is measured by evaluating sharpness.

The method we used is based on a periodic rectangle wave composition of fundamental frequency and harmonics that are sine waves. ${ }^{1}$ The flow of this method is shown in Fig. 1. The profile of a direction perpendicular to the bar of the bar patterns was created from image data and converted into the brightness value. The com- ponent value of a fundamental frequency, $M n(n$ : segment number), was calculated from exact integer cycle data extracted from the interpolated profile data. In was calculated from the bar pattern and the background levels measured from two uniform areas. The ratio of $M n$ to In was calculated for MTF.

This was the method of calculating MTF in the horizontal direction of CRT display. The LCDs are discrete display systems and are composed of individual pixels. Therefore, it is necessary to correct the results of the calculation method for the CRT display system(analog system). We multiplied MTFs by the correction factor, except for those in the horizontal direction of the CRT display.

\section{Methods}

\section{1-1 Display of bar pattern}

We used LCDs of $1 \mathrm{M}$ (about 1 million pixels), 2M, $3 \mathrm{M}$, and 5M, and a CRT display with a pixel number of $5 \mathrm{M}$. The table shows the specifications of displays. For

\title{
Summary
}

We measured modulation transfer functions (MTFs) of liquid crystal displays (LCDs) by rectangular waveform analysis. This method consists of taking a picture of the bar pattern on the display surface with a digital camera, and analyzing the picture with a personal computer. The displays used are LCDs of $1 \mathrm{M}$ (about 1 million pixels), 2M, 3M, and 5M, and a cathode ray tube (CRT) display with a pixel number of 5M. Two kinds of 2M displays were used, an in-plane switching (IPS) system and vertical alignment (VA) system, from which liquid crystal operation mode differs. MTFs increased as pixels increased. For the LCDs, MTFs in the horizontal direction were higher than those in the vertical direction except for the $2 \mathrm{M}$ VA system. For the LCD of the 2M VA system, MTF in a horizontal direction was equal to MTF in a vertical direction. For the displays with the same number of pixels $(5 \mathrm{M})$, MTF of a LCD was higher than that of a CRT display. MTFs of LCDs are influenced by the pixel form, pixel composition, and the liquid crystal operation mode.

Key words: Liquid crystal display (LCD), Cathode ray tube (CRT) display, Modulation transfer function 


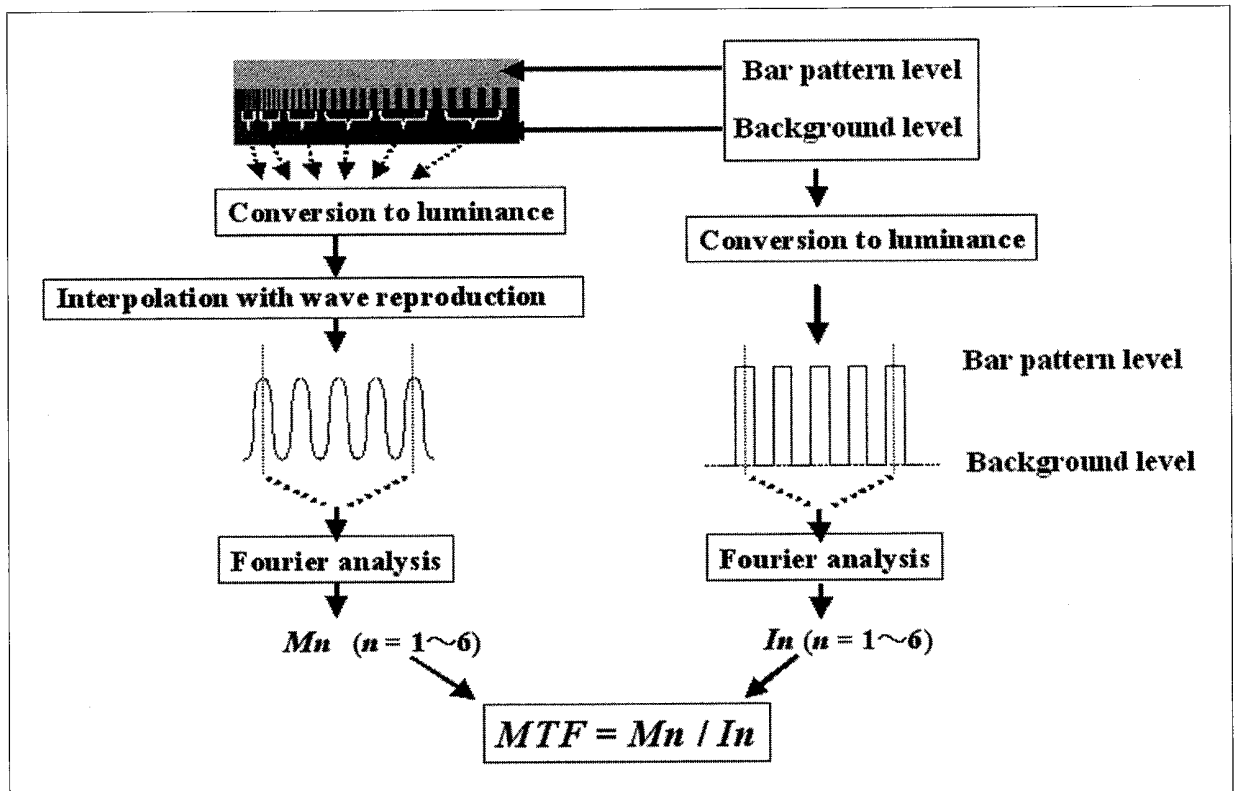

Fig. 1 Outline of the MTF measurement method using frequency analysis of a bar pattern image.

Table Specifications of displays used in this study.

\begin{tabular}{cccccl}
\hline \hline & Pixel size & $\begin{array}{c}\text { Pixel pitch } \\
{[\mathrm{mm}]}\end{array}$ & $\begin{array}{c}\text { Liquid crystal } \\
\text { operation mode }\end{array}$ & Panel maker & \multicolumn{1}{c}{$\begin{array}{c}\text { Display } \\
\text { manufacturer }\end{array}$} \\
\hline $1 \mathrm{M}(\mathrm{A})$ & $1280 \times 1024$ & 0.312 & IPS & NEC & Data-Ray (Precision 1) \\
(B) & $1280 \times 1024$ & 0.281 & IPS & ID-Tech & TOTOKU (ME181L) \\
$2 \mathrm{M}$ (VA) & $1600 \times 1200$ & 0.255 & VA & SHARP & TOTOKU (ME201L) \\
(IPS) & $1600 \times 1200$ & 0.270 & IPS & NEC & TOTOKU (ME213L) \\
$3 \mathrm{M}$ & $2048 \times 1536$ & 0.207 & IPS & ID-Tech & BARCO (MFGD3220) \\
$5 \mathrm{M}(1)$ & $2560 \times 2048$ & 0.165 & IPS & ID-Tech & NANAO (RadiForceG51) \\
$(2)$ & $2560 \times 2048$ & 0.165 & IPS & ID-Tech & TOTOKU (ME511L) \\
CRT (5M) & $2560 \times 2048$ & 0.147 & - & - & BARCO \\
\hline
\end{tabular}

the $1 \mathrm{M}$ LCDs, two kinds differing in the structure of pixels were used, and they were dubbed A and B, respectively. For the $2 \mathrm{M}$ display, two kinds also were used an in-plane switching (IPS) system and vertical alignment(VA) system $^{2)}$, from which the liquid crystal operation mode differs.

The test pattern was displayed in the center of the screen, and a photograph was taken using a digital camera (Nikon D1H, D70) and camera equipped with a macro lens (Nikon AF Micro-Nikkor). Figure 2 shows the bar pattern image used as the test pattern. There were five pairs of bars with bar pattern and background luminance levels. Each bar consisted of a 1, 2, 3, 4 and 6-pixel width, respectively. The bar level was $65 \%$ of the digital driving level(DDL), and the background level was 35\%.

The maximum luminance was set to $450 \mathrm{~cd} / \mathrm{m}^{2}$ and the minimum luminance to $1 \mathrm{~cd} / \mathrm{m}^{2}$. The displays were calibrated according to the DICOM 14 display function standard. ${ }^{3)}$ Therefore brightness of the bar level was about $98 \mathrm{~cd} / \mathrm{m}^{2}$, and those of the background level were about $21 \mathrm{~cd} / \mathrm{m}^{2}$.

\section{1-2 Picturing the bar pattern}

The measurement environment made the room dark, and luminance was about $0 \mathrm{~lx}$. The bar pattern was displayed at the center of the display. Nothing was displayed in the surrounding area except for uniform the background with low DDL and some icons. Black paper covered the display surface except for the area of the bar pattern, to exclude the influence of illumination.

To lose the inclination to the image, the camera was placed parallel to the display.

We took pictures of a bar pattern in a horizontal direction and a vertical direction. We defined horizon- 


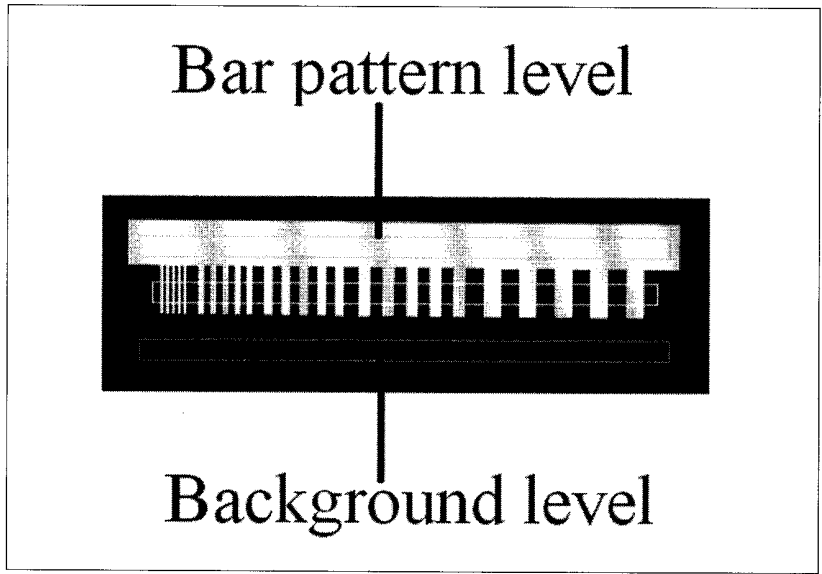

Fig. 2 Bar pattern image on display.

tal and vertical directions as portrait position and landscape position, respectively. When we took a picture of the bar pattern, the camera was not rotated, but the displays were rotated.

The distance between displays and the digital camera was adjusted so that a bar pattern would become the same size in the finder. Effective pixel number in the horizontal direction of the digital camera is 3040 . We photographed the bar pattern image to become about 2000 pixels in the horizontal direction of the digital camera. At this time, the sampling pitch in the digital camera was $0.008-0.012 \mathrm{~mm}$, and the sample number per one pixel of the display was 21-25.

The shutter speed of the camera was set to $1 / 5 \mathrm{sec}$ ond. Diaphragm was set to 29 . The matrix size of the output image was $3040 \times 2014$, and its grayscale was 12 bit. We used RAW data from the CCD for calculation.

\section{1-3 Calculation of MTFs}

The data for exact integer cycles of the bar patterns were extracted from an output waveform. The amplitude value $M n$ of a fundamental frequency of bar pattern was calculated and MTF was computed.

\section{Results}

Figures 3 and 4 show MTFs of LCDs that have different numbers of pixels with the same structure of subpixels as an IPS system. The MTFs were measured to the Nyquist frequency decided from the pixel pitch of a display. MTFs in the horizontal direction are shown in Fig. 3, and those in the vertical direction are shown in Fig. 4. These MTFs were expressed with the spatial frequency corresponding to the real distance on the screen. In the horizontal direction, MTF of 5M was the high-

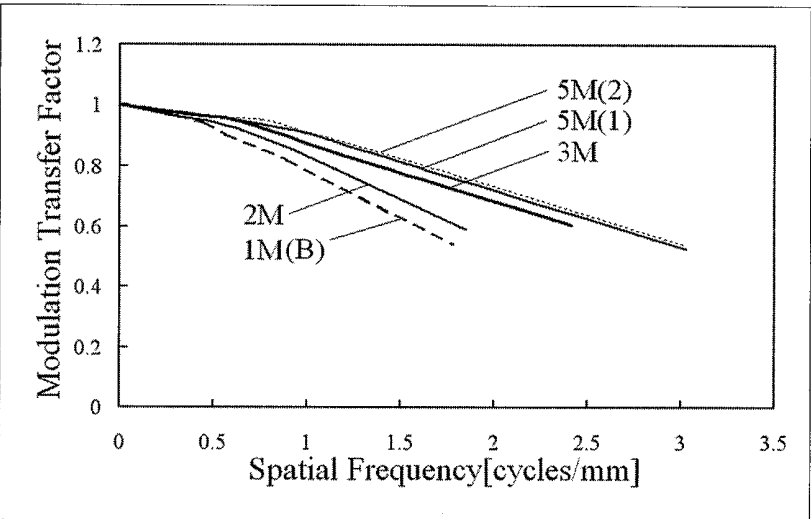

Fig. 3 MTFs in the horizontal direction of LCDs.

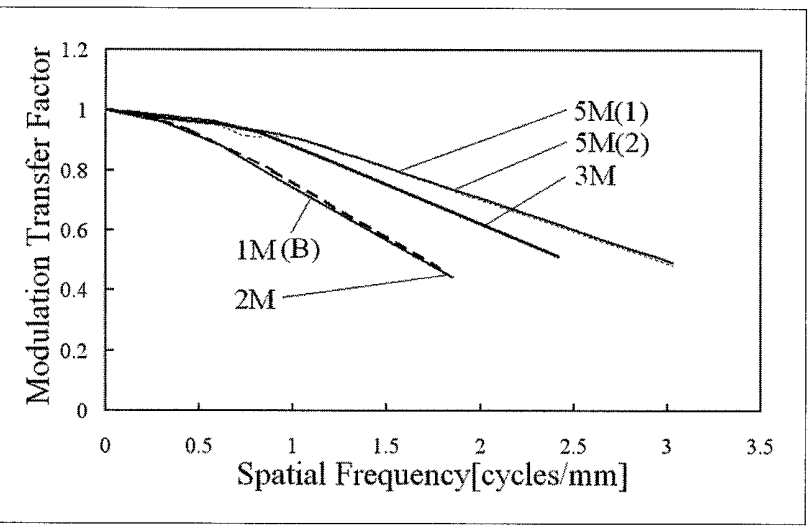

Fig. 4 MTFs in the vertical direction of LCDs.

est, compared with those of $3 \mathrm{M}, 2 \mathrm{M}$, and $1 \mathrm{M}$. The two MTFs of $5 \mathrm{M}$ were almost the same. The MTFs of $1 \mathrm{M}$ and $2 \mathrm{M}$ were similar in the vertical direction. MTFs of $1 \mathrm{M}$ displays of the LCDs that differed in the structure of pixels are shown in Fig. 5. MTFs of $1 \mathrm{M}(\mathrm{A})$ exceeded 1 at low frequency. The fluctuation was also large, and their forms were different from other MTFs. MTFs of $2 \mathrm{M}$ displays of the LCDs with differences in liquid crystal operation mode are shown in Fig. 6. MTFs of the VA system in the horizontal and vertical directions were almost the same. MTFs of 5M displays of the LCD and CRT displays are shown in Fig. 7. MTFs of the CRT display decreased considerably compared with those of the LCD as frequency increased.

\section{Discussion}

Enlarged images of pixels are shown in Fig. 8. We found that the shape of a pixel of $1 \mathrm{M}(\mathrm{A})$ was diamondlike and differed from other displays. Moreover, the width of a bar with one pixel was effectively narrower than 


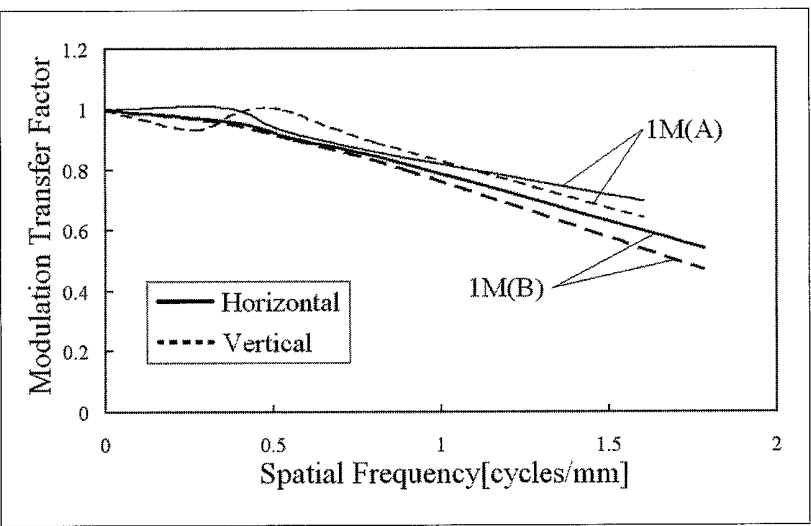

Fig. 5 MTFs of LCDs of $1 \mathrm{M}$ that differ in pixel structure.

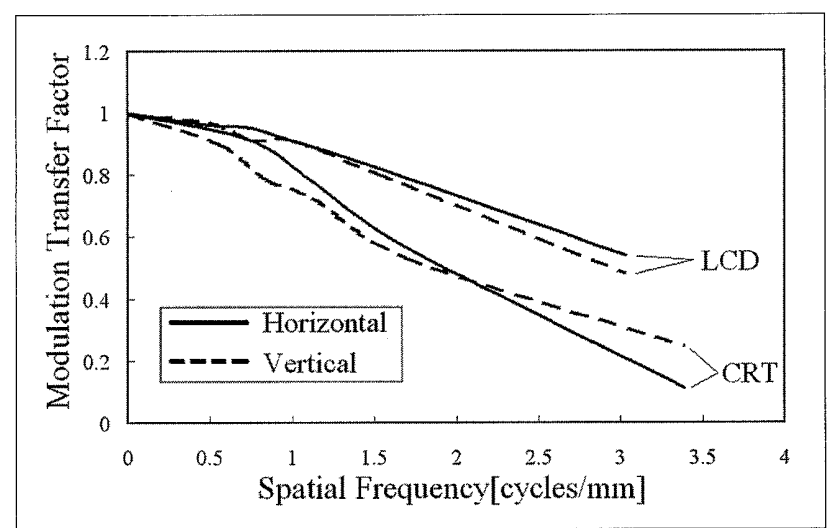

Fig. 7 MTFs of the LCD and the CRT display of 5M.

those of other displays. Therefore, we consider that the MTFs of $1 \mathrm{M}(\mathrm{A})$ increased by the difference in this structure of sub-pixels.

Enlargements and the schematic diagrams of pixels with a $2 \mathrm{M}$ (VA) system, 3M, and 5M, IPS systems, are shown in Fig. 9. The shape of a pixel of 2M(VA) was rectangular or almost square. This indicates that MTFs of a VA system in the horizontal and vertical directions were almost the same. In the IPS system, the boundary of a pixel in the horizontal direction was mostly straight, but the boundary of a pixel in the vertical direction was zigzag when the shape of the pixel was not rectangular. Therefore, the boundary of a "zigzag" bar faded, and was considered to decrease MTF in the vertical direction.

The LCD display was controlled by a thin-film transistor. In the case of CRTs, it was controlled by the inclination of the electron beam in CRT displays. In CRT displays, dispersion of the light according to spot size and the fluorescent substance of the electronic beam were

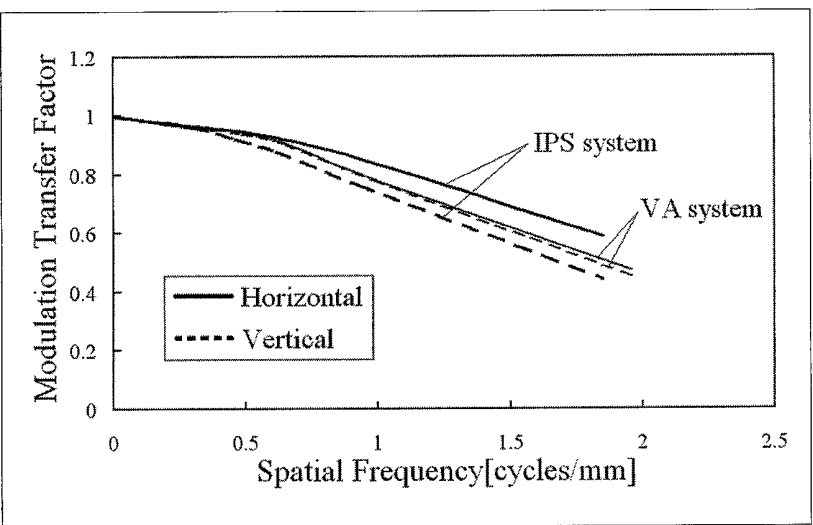

Fig. 6 MTFs of LCDs of $2 \mathrm{M}$ that differ in the operation mode of liquid crystal.

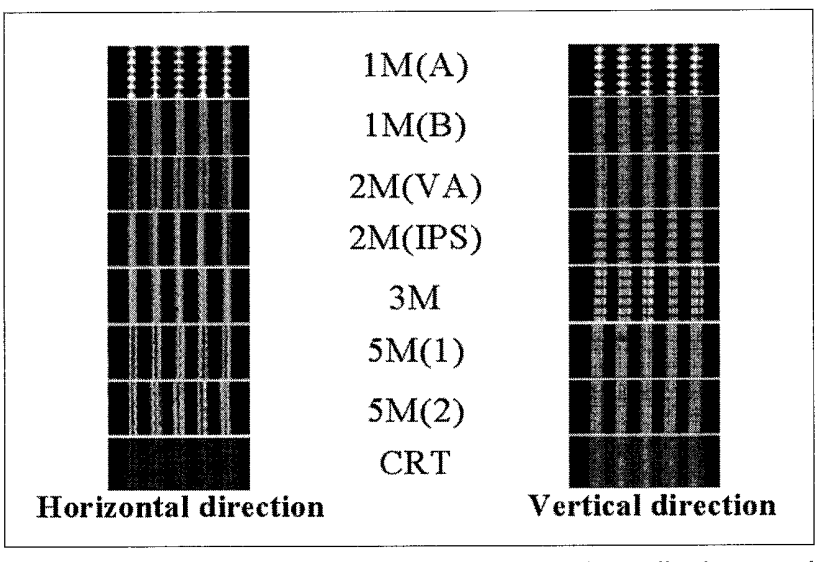

Fig. 8 Enlarged pictures of LCDs and the CRT display used in this study.

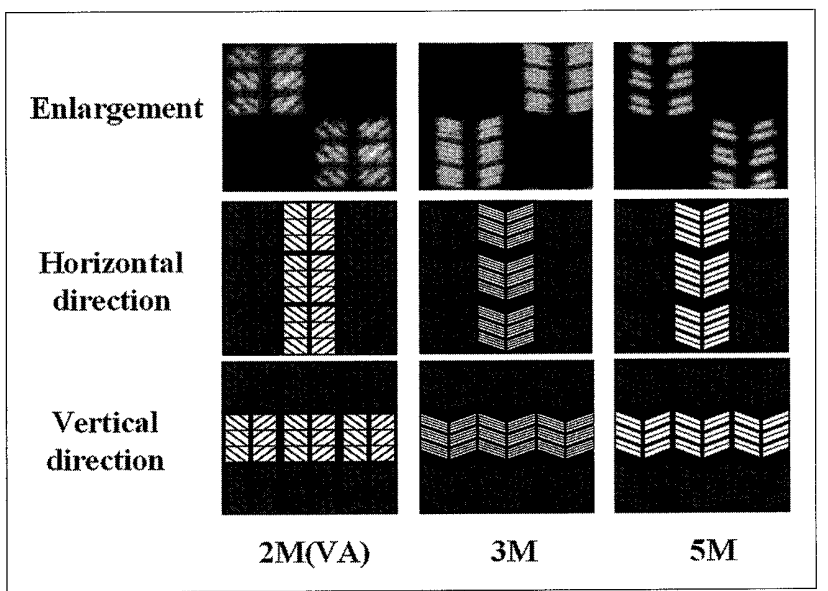

Fig. 9 Structure of sub-pixels of LCDs used in this study. Upper layer is an enlargement of pixels. Middle and lower layers are schematic diagrams of pixels. Middle layer shows pattern diagrams when the bar of one pixel is horizontally displayed. Lower layer shows pattern diagrams when the bar of one pixel is vertically displayed. 
the factors responsible for lack of sharpness.

There has been much research regarding MTFs in the horizontal direction of a CRT display. ${ }^{4)}$ However, research is very limited regarding MTFs in the vertical direction of CRTs and the MTFs of LCDs. This is because these characteristics are discrete. We suggested a method of measuring MTF in the case of a discrete value. It has recently begun to be used to measure the MTFs of LCDs, and it remains to be determined what kind of influence the values will have on diagnosis.

\section{Conclusion}

We measured the MTFs of LCDs and a CRT display. The MTFs of LCDs were affected by differences in size, pixel shape, structure, and operation mode of the liquid crystal, as well as by the number of pixels. MTFs of the LCD were higher than those of the CRT display.

\section{References}

1) Ichikawa K, and Fujita H: An MTF Measurement Method of a Medical Image Viewer Using a Bar Pattern. Journal of Photographic Science and Technology, 67, 184-190,(2004).

2) Koden M: Wide Viewing Angle Technologies of TFT-LDEs. SHARP Technical Journal, 74 (8), 55-59, (1999).
3) Digital Imaging and Communications in Medicine (DICOM), Part 14: Grayscale Standard Display Function.

4) Kanazawa M, Kondoh I, Sugiura Y, et al.: Measurement Method of a Display's MTF. The Institute of Image Information and Television Engineers, 55 (5), 760-772,(2001).

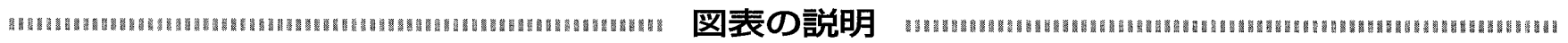

Fig. 1 バーパターンを用いた医用画像ビューアのMTF測定法の流れ

Fig. 2 ディスプレイに表示するバーパターン画像

Fig. 3 液晶ディスプレイの水平方向のMTF

Fig. 4 液晶ディスプレイの垂直方向のMTF

Fig. 5 1Mのサブピクセルの構造が異なる 2 種類の液晶ディスプレイのMTF

Fig. $62 \mathrm{M}$ の液晶動作モードの異なる 2 種類のディスプレイのMTF

Fig. 7 5Mの液晶デイスプレイとCRTディスプレイのMTF

Fig. 8 今回の研究で用いた液晶ディスプレイとCRTディスプレイのバーを撮影した画像の拡大図

Fig. 9 今回の研究で使用した液晶ディスプレイのサブピクセルの構造

上段 : 画素の拡大図

中段：1 画素幅のバーを水平に表示した場合の模式図

下段：1 画素幅のバーを垂直に表示した場合の模式図

Table 